\title{
Active Immunisation with Partner Lymphocytes in Female Patients Who Want to Become Pregnant - Current Status
}

\section{Aktive Immunisierung mit Partnerlymphozyten bei Kinderwunsch- patientinnen - der aktuelle Stand}

\section{(우(1) (옹}

\author{
Authors \\ Sören von Otte ${ }^{2}$ \\ Affiliations \\ 1 Klinik für Gynäkologie und Geburtshilfe, UKSH Campus \\ Kiel, Kiel, Germany \\ 2 Universitäres Kinderwunschzentrum, MVZ, Universitäts- \\ klinikum Schleswig-Holstein, Campus Kiel, Kiel, Germany \\ 3 Institut für Transfusionsmedizin, UKSH Campus Kiel, Kiel, \\ Germany \\ 4 Institut für Transfusionsmedizin, UKSH Campus Lübeck, \\ Lübeck, Germany
}

Veronika Günther ${ }^{1}$, Ibrahim Alkatout ${ }^{1}$, Wiebe Junkers², Nicolai Maass ${ }^{1}$, Malte Ziemann ${ }^{3,4}$, Siegfried Görg ${ }^{3,4}$,

Key words

miscarriage, immunology, implantation, immunisation, partner lymphocytes

Schlüsselwörter

Abort, Immunologie, Implantation, Immunisierung, Partnerlymphozyten

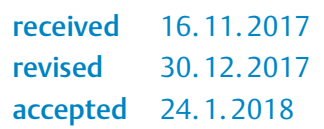

Bibliography

DOI https://doi.org/10.1055/s-0044-101609

Geburtsh Frauenheilk 2018; 78: 260-273 @ Georg Thieme Verlag KG Stuttgart · New York | ISSN 0016-5751

\section{Correspondence}

Dr. med. Veronika Günther

Klinik für Gynäkologie und Geburtshilfe, UKSH Campus Kiel Arnold-Heller-Straße 3 (Haus 24), 24105 Kiel, Germany Veronika.Guenther@uksh.de

$\Theta$

Deutsche Version unter: https://doi.org/10.1055/s-0044-101609

\begin{abstract}
Around $1-3 \%$ of all couples who try to have a child are affected by recurrent miscarriage. According to the WHO, recurrent miscarriage is defined as the occurrence of three or more consecutive miscarriages up to the 20th week of pregnancy. There are various causes of recurrent miscarriage; in many cases, the causes remain unclear, with the result that immunological factors are one of the possible causes discussed. For the mother's immune system, the embryo represents a semi-allogeneic transplant, as half of the embryo's genes are of paternal origin. In place of a conventional immune response, the embryo induces a secondary protection mechanism, which contributes to the successful implantation. When performing immunisation with partner lymphocytes, the patient receives an intradermal injection of her partner's prepared lymphocytes into the volar side of the forearm in order to induce immunomodulation with a consequently increased rate of pregnancy and live birth. A prerequisite for this procedure is that all other possible causes of sterility have been ruled out in advance. Due to the highly heterogeneous nature of the data, a significant benefit as a result of the immunisation cannot yet be clearly proven. However, there are signs that the therapy may be effective when using lymphocytes that have been extracted as short a time beforehand as possible. Overall, the treatment represents a safe, low-risk procedure. Following a detailed informative discussion with the couple regarding the chances of success and following a detailed review of the indication and contraindications, immunisation with partner lymphocytes can be discussed with the couple on a case-by-case basis - provided that all other possible causes of sterility have been ruled out in advance.
\end{abstract}

\section{ZUSAMMENFASSUNG}

Etwa 1-3\% aller Kinderwunschpaare sind von einem habituellen Abortgeschehen betroffen. Dies ist laut WHO definiert als das Auftreten von 3 oder mehr aufeinanderfolgenden Aborten bis zur 20. SSW. Die Ursachen hierfür sind vielfältig, bleiben in einer Vielzahl der Fälle sogar unklar, sodass unter anderem immunologische Faktoren diskutiert werden kön- 
nen. Der Embryo stellt für das Immunsystem der Mutter ein semiallogenes Transplantat dar, da die Hälfte der Gene des Embryos paternaler Herkunft sind. Anstelle einer üblichen Immunantwort induziert der Embryo einen sekundären Schutzmechanismus, welcher zur erfolgreichen Implantation beiträgt. Bei der Immunisierung mit Partnerlymphozyten werden der Patientin aufbereitete Lymphozyten ihres Partners in die volare Seite des Unterarms intrakutan injiziert, um so eine Immunmodulation mit konsekutiv erhöhter Schwangerschaftsund Lebendgeburtenrate zu induzieren. Voraussetzung für dieses Verfahren ist, dass zuvor alle anderen infrage kommenden Sterilitätsursachen ausgeschlossen wurden. Aufgrund der äußerst heterogenen Datenlage kann ein signifikanter Nutzen durch die Immunisierung immer noch nicht eindeutig belegt werden. Es gibt jedoch Hinweise, dass die Therapie bei Verwendung möglichst frisch entnommener Lymphozyten wirksam sein könnte. Die Behandlung stellt insgesamt ein sicheres und risikoarmes Verfahren dar. Nach ausführlicher Aufklärung des Paares über die Erfolgsaussichten und genauer Überprüfung von Indikation und Kontraindikationen kann individuell mit dem Paar eine Immunisierung mit Partnerlymphozyten diskutiert werden - vorausgesetzt, zuvor wurden alle anderen infrage kommenden Sterilitätsursachen ausgeschlossen.

\section{Introduction}

As a sign of low reproductive efficiency, couples who are trying to have a child may suffer from failure to conceive following multiple embryo transfers. On the other hand, rapid and unproblematic spontaneous conception may be followed by recurrent loss of the pregnancy within the context of a miscarriage.

Recurrent miscarriage is defined as the occurrence of three or more consecutive miscarriages up to the 20th week of pregnancy [1], with the American Society for Reproductive Medicine (ASRM) defining recurrent miscarriage as just two consecutive miscarriages [2]. $1 \%$ of couples is affected by recurrent miscarriage. The probability of a repeat miscarriage rises as the number of previous miscarriages increases [1]. There are various causes of recurrent miscarriage, including a combination of several factors. Examples of causes include: chromosomal causes (balanced translocation, inversion, mosaic), infections (toxoplasmosis, chlamydia), endocrine causes (PCO, hyperandrogenaemia, hyperprolactinaemia, hyper/hypothyroidism), coagulation disorders (Factor $\mathrm{V}$ Leiden mutation, prothrombin mutation), autoimmune diseases (lupus erythematosus, antiphospholipid syndrome), congenital or acquired uterine anomalies (uterine septum, uterus myomatosus) [3]. However, in around $40 \%$ of cases, the cause remains unclear, with the result that immunological factors are one of the possible causes discussed [4].

From the development of the blastocyst through to implantation, an intensive immunological interaction is required between the embryo and the maternal immune system. During the buildup of the extraembryonic membranes, the trophoblast is incorporated into the decidua, erodes maternal blood vessels and therefore maintains the foetomaternal exchange of blood substances and nutrients. As a result of this process, direct contact is established between maternal blood and foetal cells, the syncytiotrophoblasts. The trophoblast invasion into the maternal decidua is influenced by immunological effector cells, in particular the uterine natural killer cells (uNK) (see below) [11]. With the help of the vascular endothelial growth factor (VEGF) and interferon gamma (INF-gamma), they stimulate the conversion of the spiral arteries and are involved in the regulation of the invasion depth. The pregnant uterus can be described as an immune-privileged site, in that the balance between organ preservation and infection defence is significantly shifted in favour of organ preservation. In order to nevertheless provide effective protection from pathogens for the uterus, there are a large number of immunocompetent cells in the decidua, which belong to the innate, and therefore antigen-independent, immune defence. The dendritic cells (DC) take on a special function in the decidua: On the one hand, they can induce antigen-specific cytotoxic T-cell immune responses and, on the other hand, they ensure immunological tolerance under steadystate conditions $[5,6]$.

In addition, local immunoactive substances, such as galectins and glycodelin, are secreted by glandular uterine epithelial cells [7]. Fig. 1 shows the foetomaternal interface with the cells responsible for a successful implantation.

For the mother's immune system, the embryo represents a semi-allogeneic transplant, as half of the embryo's genes are of paternal origin. In place of a conventional immune response, the embryo induces a secondary protection mechanism [8]. The first theories regarding the explanation of this form of "immune tolerance" were described by Medawar in 1953:

1. He assumed a strict anatomical separation between maternal and foetal tissues by means of the placenta.

2. A further hypothesis described the embryo as non-immunogenic, stating that it therefore follows that the embryo cannot generate an immune response.

3. The third theory assumed a maternal immune response that had been weakened by the pregnancy $[9,10]$.

\section{HLA (Human Leukocyte Antigens)}

The last assumption was modified by the concept of the "protective immune response". This was supported by examinations of human leukocyte antigens (HLA), surface proteins of leukocytes and other tissues ( $\triangleright$ Fig. 2, Major histocompatibility complex [MHC]). The $\mathrm{HL}$ antigens form the individual signature of the cells and play the key role when the immune system is differentiating between endogenous and exogenous structures. Monozygotic twins and $25 \%$ of siblings have an identical HLA pattern.

The extravillous trophoblast invading the decidua does not express the conventional HLA Class I or Class II protein complexes, but rather non-conventional human leukocyte antigens, in particular HLA-G, which are of great importance for the success of the pregnancy. HLA-G inhibits the activity of natural killer cells (NK cells) and type $1 \mathrm{~T}$ helper cells ( $\mathrm{T}_{\mathrm{H}} 1$ cells) and thereby prevents 


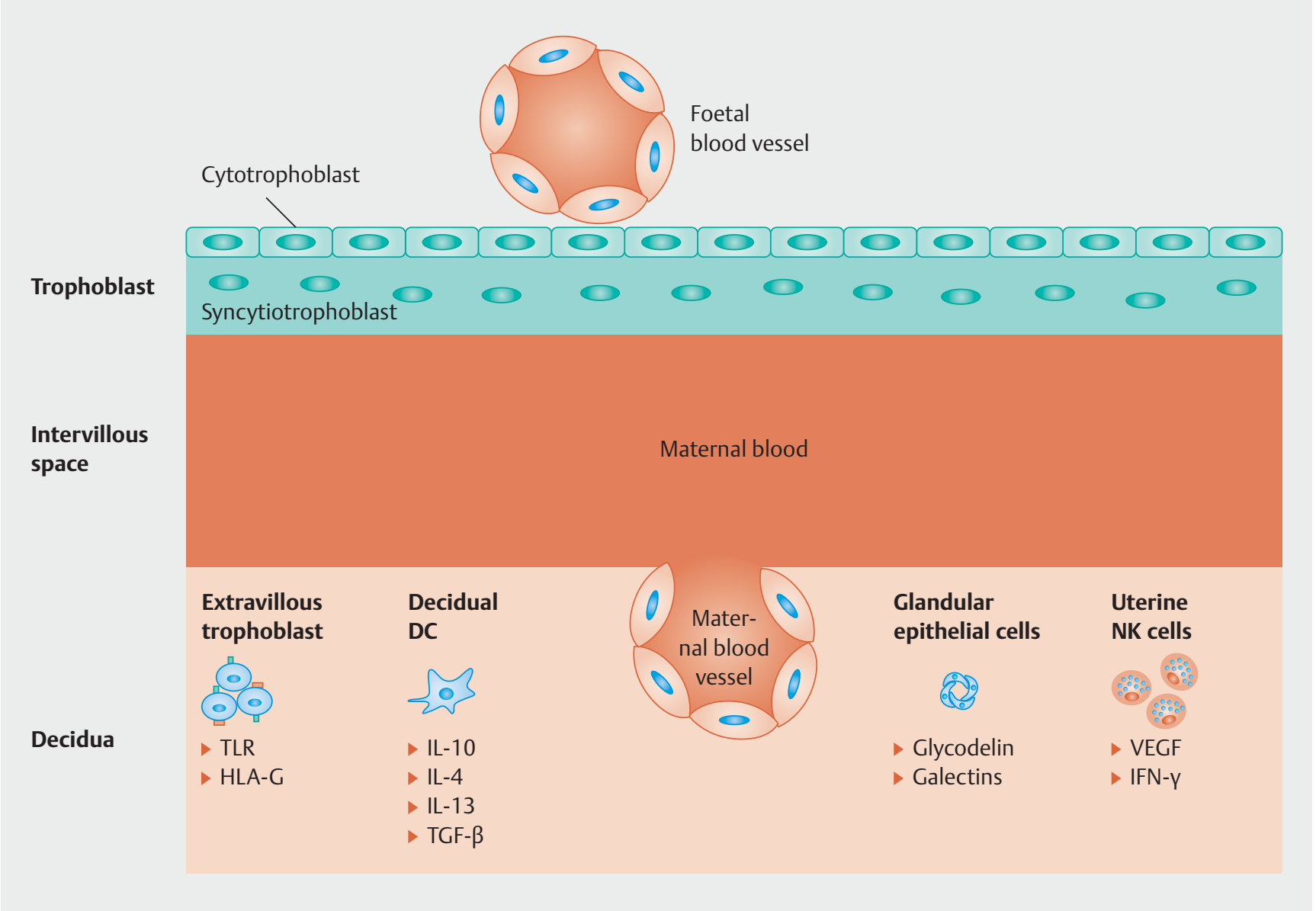

- Fig. 1 Immunocompetent cells of the foetomaternal interface (according to [17]). In the intervillous space, the trophoblast is in direct contact with the maternal blood. There is a special cellular immunological environment in the decidua. The individual cellular components with their most important molecules are presented here. TLR: toll-like receptor; DC: dendritic cells; TGF-beta: transforming growth factor; uNK cells: uterine natural killer cells; VEGF: vascular endothelial growth factor; IFN-gamma: interferon gamma.

the rejection of the semi-allogeneic embryo. With their regulation and secretion of cytokines and chemokines, the uterine natural killer cells (uNK cells) are responsible for this [11, 13-15]. In addition, the trophoblast expresses pathogen recognition receptors on its surface, known as toll-like receptors (TLR), which trigger a tissue and pathogen-specific immune response following activation [12].

\section{Natural Killer Cells (NK)}

$\mathrm{CD}^{+} 6^{+}$cells, known as natural killer cells (NK cells), represent a primary component of the innate, non-specific immune system. They destroy those somatic cells whose HLA molecules are genetically coded as "foreign" or are modified by infection, such as tumour or virus-modified cells, without previous recognition of a specific antigen. The rapid and non-antigen-dependent elimination of such cells represents an important form of protection against viral diseases and tumour cells, but, at the same time, it poses the risk of autoimmunity. For this reason, the cytotoxic mechanisms of the NK cells are strictly regulated and their matu- ration requires a specific environment, e.g. one shaped by cytokines and chemokines.

A factor in the changing maternal immune system is the pregnancy-related decrease in natural killer cells (NK) and their production of interferon gamma (IFN- $\gamma$ ). A missing decrease in maternal peripheral killer cells is associated with an increased rate of miscarriage $[19,20]$.

Uterine natural killer cells (uNK) amount to around $70 \%$ of the immune cells in the foetomaternal interface and they represent a special type of cell shaped by the immunological environment; these cells differ significantly from the peripheral blood NK cells [16]. uNK have significantly more secretory than cytotoxic properties. The uNK cells are inhibited by the HLA-G expressed by the trophoblast [17]. uNK cells have a lytic function within the context of the conversion of the spiral arteries [18]. The secretion of interferon gamma, and of other vasoactive substances, such as vascular endothelial growth factor (VEGF), is important for the development of the placental immune architecture, as well as the vascularisation of the placenta $[19,20]$. 


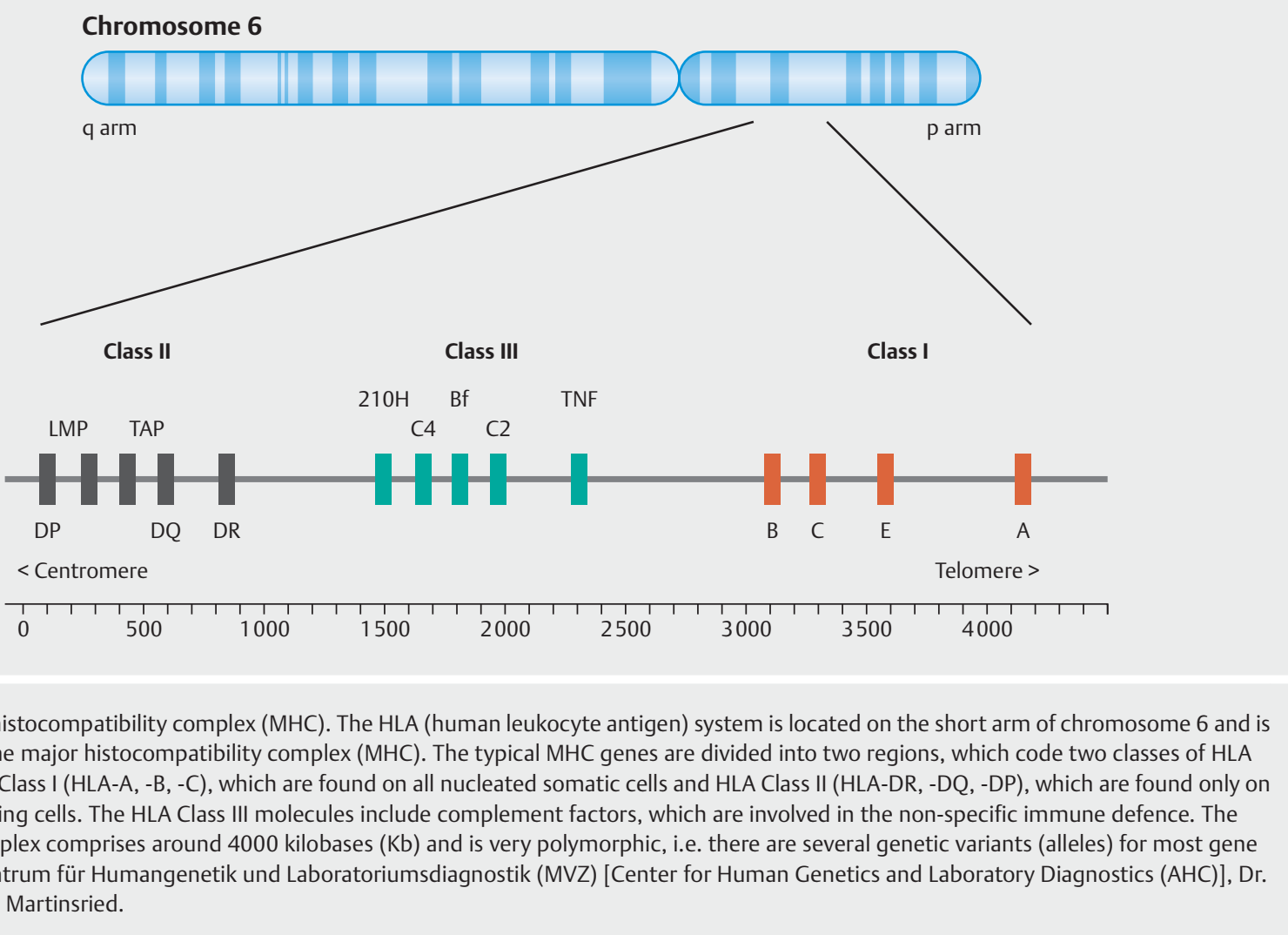

\section{T Lymphocytes}

The regulatory $T$ cells $\left(T_{\text {reg }}\right)$, previously also known as T suppressor cells, are responsible for the self-tolerance of the immune system and prevent the occurrence of autoimmune diseases. They undergo a physiological increase during pregnancy. If this mechanism does not occur, recurrent miscarriages are observed [19].

The T helper cells are a group of T lymphocytes and they have a supporting, "helping" role to play with regard to the immune response. Two subgroups of T helper cells can be described according to the cytokines they secrete: Type $1 \mathrm{~T}$ helper cells are involved in the cellular immune response and release interferon gamma (IFN-y), interleukin-2 (IL-2) and tumour necrosis factor alpha (TNF- $\alpha$ ). In this regard, cytotoxic T cells destroy infected cells, for example as a response to a viral infection. In contrast, type $2 \mathrm{~T}$ helper cells are involved in the humoral immune response and secrete the cytokines IL-4, IL-5, IL-9, IL-10 and IL-13. These cytokines strengthen antibody production as well as the proliferation and function of eosinophil granulocytes. $T_{H} 1$ responses suppress $T_{H} 2$ responses and vice versa.

The cytokines of the $T_{H} 1$ and $T_{H} 2$ cells influence implantation as well as foetal development and differentiation.

In 1993, Wegmann et al. described the theory of a balance between the $T_{H} 1 / T_{H} 2$ cytokines and stressed that foetal survival is only possible if the $\mathrm{T}_{\mathrm{H}} 2$ cytokines are dominant compared to the $\mathrm{T}_{\mathrm{H}} 1$ cytokines (so-called "shift" in favour of the type $2 \mathrm{~T}$ helper cells over the type $1 \mathrm{~T}$ helper cells) [21]. In the following years, further studies were carried out, which confirmed this hypothesis and concluded that an increased level of $\mathrm{T}_{\mathrm{H}} 1$ cytokines (INF- $\mathrm{\gamma}$, IL2 and TNF- $\alpha$ ) is associated with an increased rate of miscarriage $[22,23]$. TNF- $\alpha$ suppresses the growth of the trophoblast by inducing apoptotic processes in its cells $[18,19]$.

Although it was demonstrated that cytokines are essential during pregnancy, the $T_{H} 1 / T_{H} 2$ paradigm changed to the effect that the $T_{H} 2>T_{H} 1$ dominance should not be presented in such a dogmatic manner. The cytokine networks are structured in a highly synergistic and redundant manner, with the result that it is difficult to examine and assess individual cytokines in detail. More recent investigations see an epiphenomenon of a modified hormone and cytokine balance as being responsible for the successful outcome of a pregnancy, rather than the presence of a very dominating $T_{H} 2$ cytokine pattern [24].

The individual immune response stages in the early phase of pregnancy have not yet been clarified in detail and require further research. If dysregulation occurs within the individual meticulous stages of immunomodulation, this results in a miscarriage rate of up to $50 \%[25,26]$.

For couples trying to have a child who are suffering from recurrent miscarriage, there are many therapy approaches aimed at exerting a modulating effect on the immune system in order to thereby increase the pregnancy rate. In addition to active immunisation with partner lymphocytes, there is also a range of additional immune therapies designed to have a positive effect on implantation rates, such as glucocorticoid administration, intralipid infusions, intravenous immunoglobulin administration and therapy with anti-TNF- $\alpha$ agents $[3,27,28]$. Of these various therapies, 
immunisation with partner lymphocytes has been subject to most investigation [29, 30].

In addition to a direct influence on the immune system, immunological therapy approaches could also have an impact on psychological causes of recurrent miscarriage in the form of a placebo effect. "Tender loving care" (TLC) is one of the concepts that emphasises the importance of psychological factors [31, 32]. Within the context of this concept, the pregnant woman is subject to close monitoring from both a clinical and psychosomatic perspective, e.g. regular ultrasounds during the early stages of pregnancy, which go well beyond the designated scope of prenatal care. Stray-Pedersen divided women suffering from recurrent miscarriage for whom anatomical causes had been ruled out into two groups: One group received psychological support as well as close gynaecological monitoring and the other group did not. Significantly higher pregnancy rates were observed in the patients in the TLC group (86 vs. 33\%; $p<0.001$ ) [31]. Despite good results, the TLC concept is still missing scientific validation by means of randomised controlled studies in terms of evidence-based medicine. As such, it would appear that further studies are needed in this regard.

In observational studies, a possible immunological effect cannot be distinguished from the placebo effect of the therapy. Only placebo-controlled studies can therefore be used to assess the immunological effect.

\section{Immunomodulation by Means of Active Immunisation with Partner Lymphocytes}

Before preparations for the immunisation can start, certain prerequisites for both partners must be reviewed: contraindications for the female recipient include, for example, the presence of an autoimmune disease (lupus erythematosus, antiphospholipid syndrome, Crohn's disease, ulcerative colitis or multiple sclerosis), chronic diseases that may necessitate a transplant at a later date (diabetes mellitus, cystic fibrosis, polycystic kidney disease) or transplants in the medical history. If the partner has an increased risk of transmitting infectious diseases or malignant cells, he will not be approved for a lymphocyte donation.

The aim of the active immunisation with partner lymphocytes is to stimulate the immune system, thereby leading to improved immunorecognition in the subsequent pregnancy. The active immunisation was developed and used for the first time in the 1980s.

As a general rule, whole blood is taken from the partner and the lymphocytes are isolated from the whole blood by means of density gradient centrifugation. Under sterile conditions, the lymphocytes are washed multiple times and then suspended in saline solution. Partner lymphocytes are currently classified as advanced therapy medical products (ATMP) in Germany, as the lymphocytes play a different role in the patient's body than they would in the donor's body. A manufacturing authorisation and processing in a cleanroom are therefore required. The finished product is usually administered to the patient in the form of an intracutaneous injection into the volar side of a forearm. A test for antipaternal HLA antibodies can be carried out 4-6 weeks after immunisation.
If the production of antibodies is detected, the couple should aim for a pregnancy within the following 12 months; otherwise, the immunisation can be repeated.

The immunisation should strengthen the maternal immune response, which is aimed at paternal antigens on the trophoblast. The detection of antipaternal antibodies indicates that the immunisation has induced a maternal immune response [33]. In the literature, there are several studies that describe an increased pregnancy rate following immunisation associated with the simultaneous presence of antipaternal antibodies [33-35]. Carp et al. also established a connection between positive detection of antibodies following immunisation and successful pregnancy: $50 \%$ of patients in whom antibodies were detected fell pregnant, but this figure was just $37 \%$ when there were no antibodies detected [33]. However, it is unknown whether the antipaternal HLA antibodies exert a direct effect or whether they are simply a marker for the successful modulation of the maternal immune system.

Possible complications and the side effects profile following immunisation are roughly equivalent to those following intradermal vaccination against viral infectious diseases. Possible side effects include local reactions, such as redness, swelling or burning; rarer side effects include systemic, flu-like symptoms, which occur in $8 \%$ of cases. There is no particular risk of anaphylaxis or autoimmune diseases [36,37]. Despite previous testing on viral diseases, the transmission of infections cannot be completely ruled out.

The efficacy of the method has been assessed in numerous studies and overview analyses. - Table 1 shows an overview of the randomised studies, which have been included in the current meta-analyses of Wong et al., 2014 [28], Liu et al., 2016 [38] and Cavalcante et al. 2017 [39] [40-62]. In addition to the study design and the number and age of the patients enrolled, the table also lists the time, dosage and administration route of the immune therapy, the substance for the treatment group and the placebo group, the outcome regarding live birth and/or advanced pregnancy, as well as information regarding success monitoring, storage or other particular characteristics.

The first meta-analysis regarding immunisation with partner lymphocytes was published in 1993 by Fraser et al. [63]. In this case, 4 randomised studies regarding immunotherapy with lymphocytes or infusion of trophoblast membranes were carried out. The studies showed no improvement with regard to the rate of live births [63].

In 1991, during the 11th annual meeting of the American Society for Reproductive Immunology, the Ethics Committee of the Society for Immunotherapy initiated a multicenter study to standardise the treatment protocol and increase the study size. To this end, data was compiled from 15 sites. Nine randomised studies were analysed by two independently operating analysis teams. It was demonstrated that there was an increased rate of live births following immunotherapy in female patients suffering from recurrent miscarriage (odds ratio [OR] 1,16, 95\% confidence interval [95\% CI] 1.04-1.34). A significant increase in the rate of live births was described when antipaternal HLA antibodies were detected in the mother before the pregnancy ( $R R$ 1.17, 95\% Cl 1.06-1.27) [54]. 


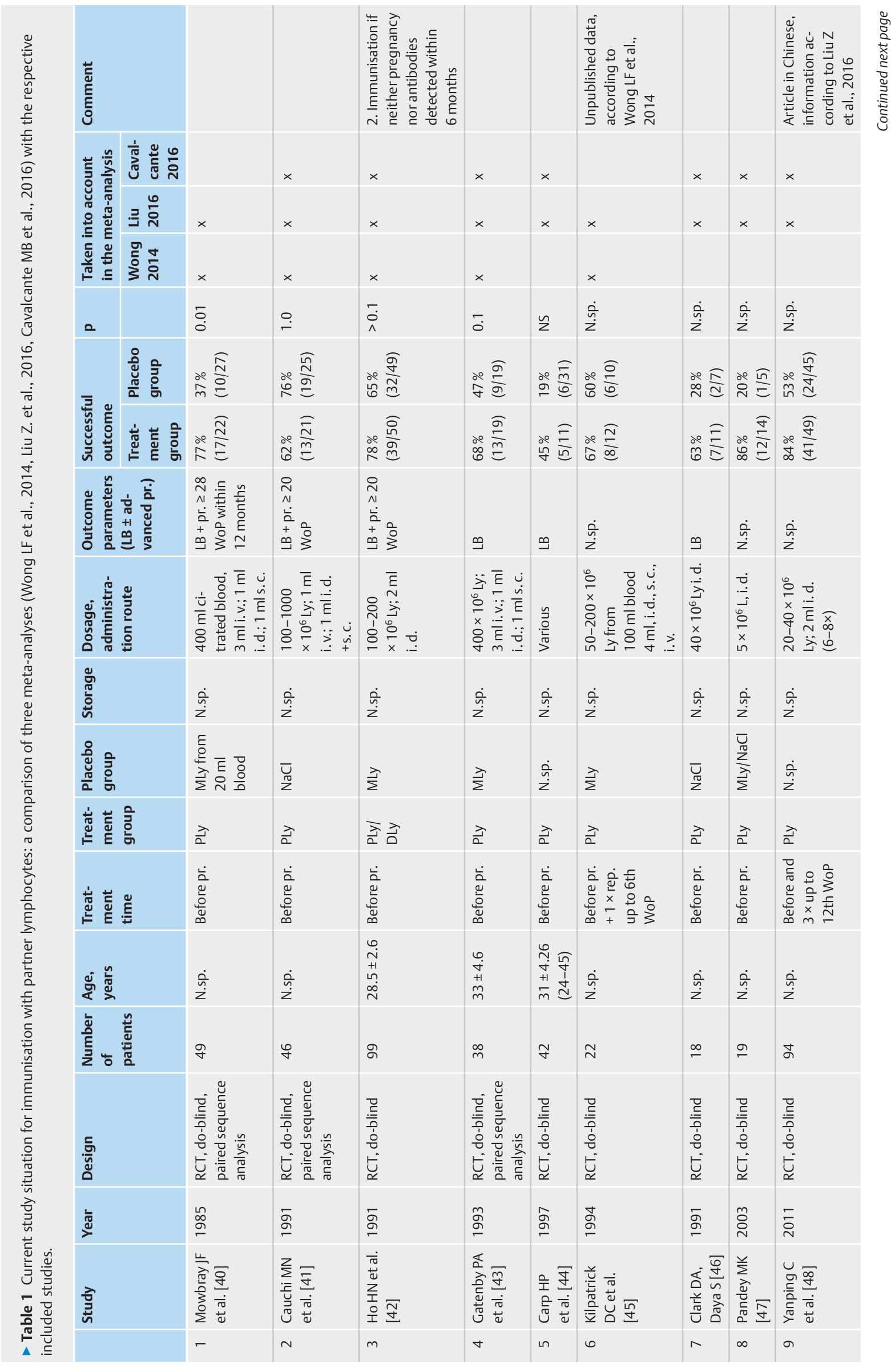




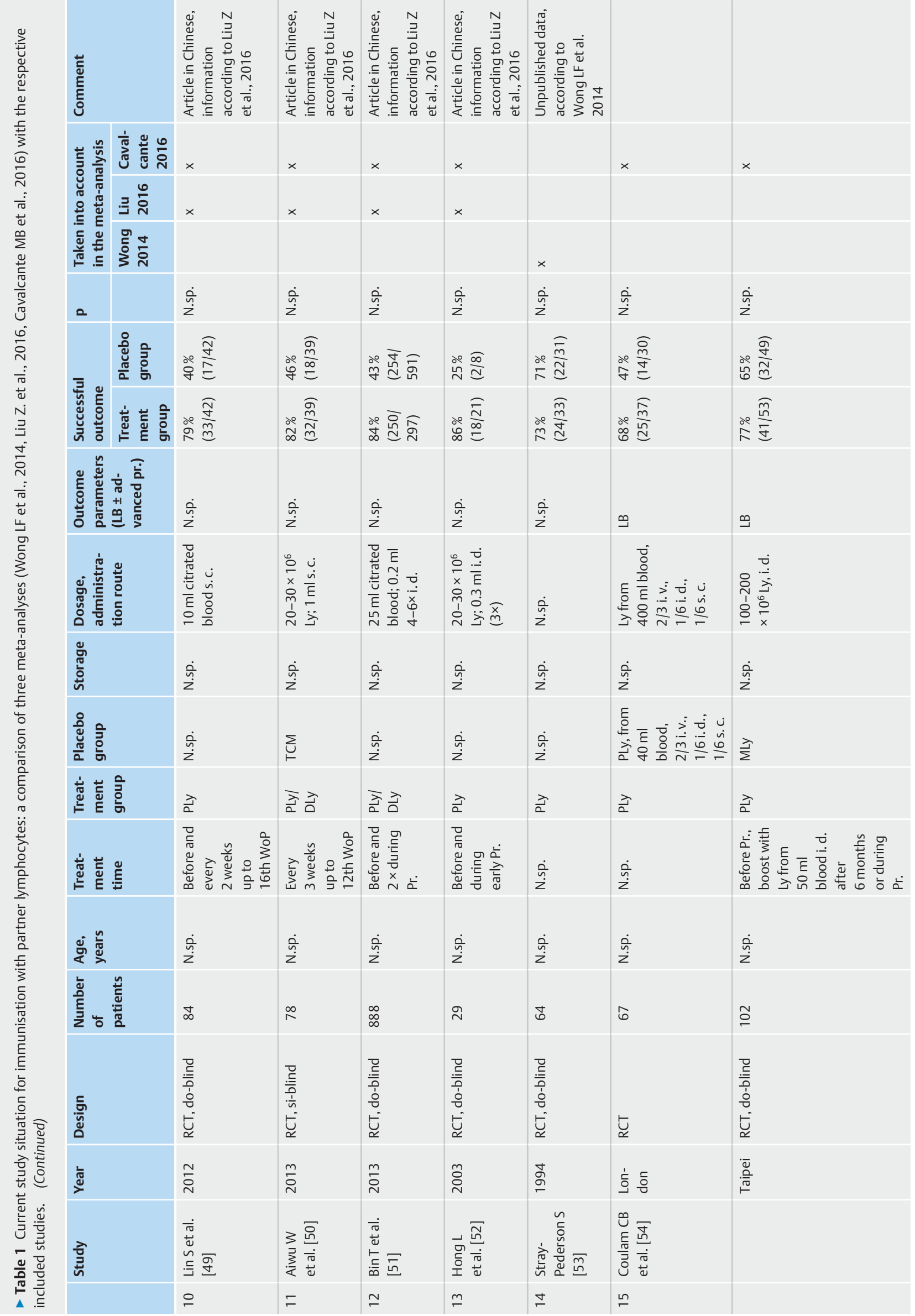




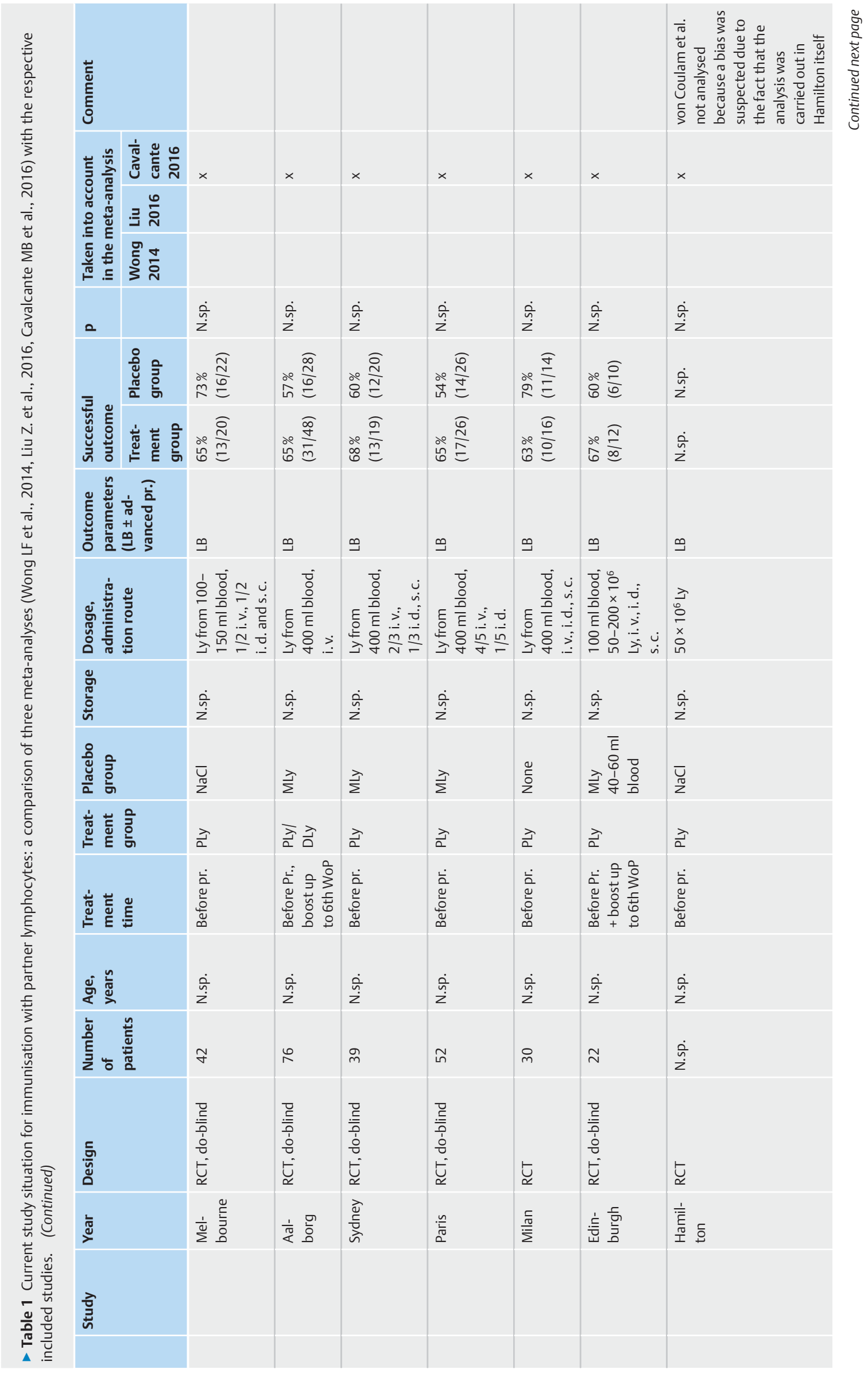




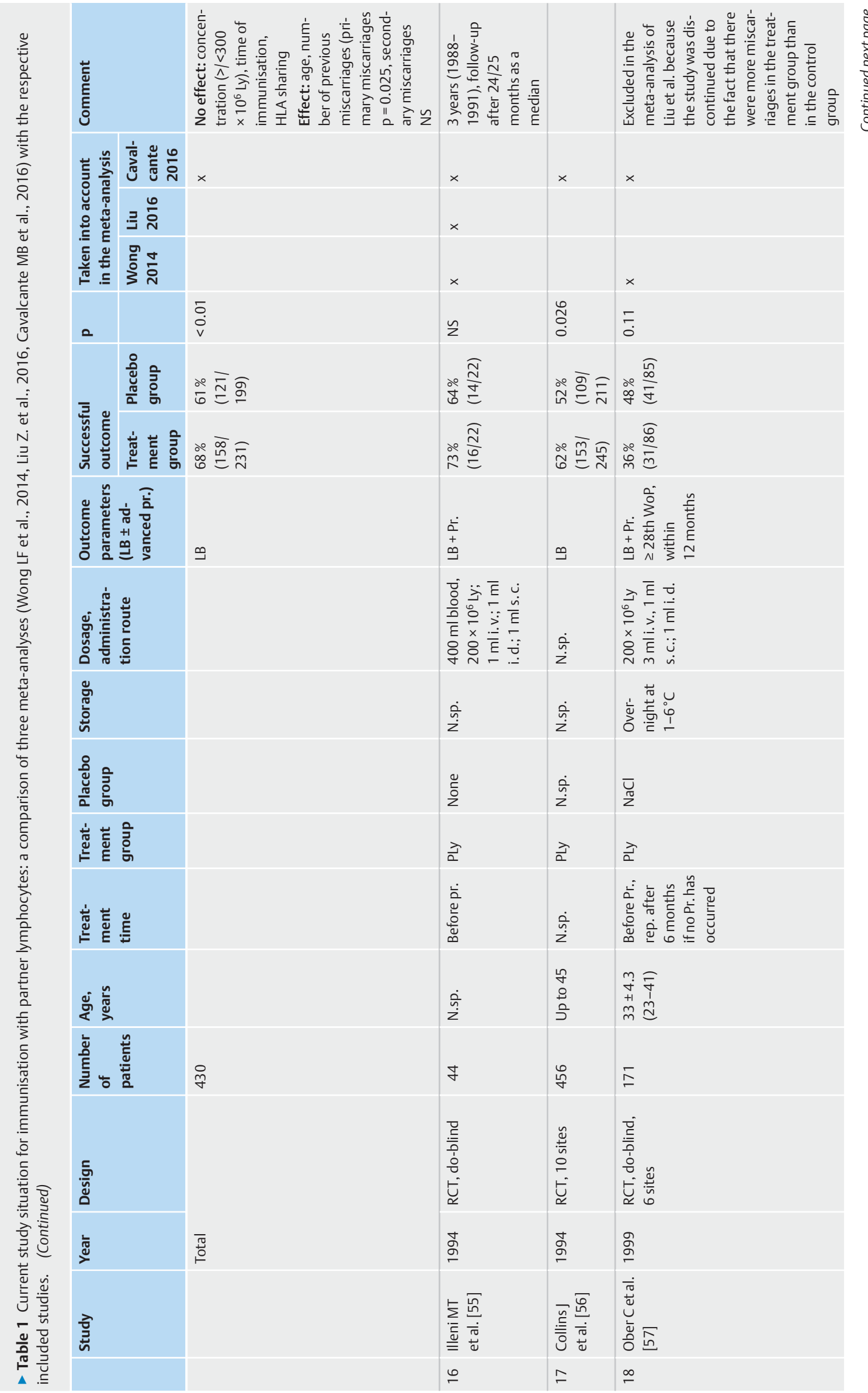




\begin{tabular}{|c|c|c|c|c|c|c|c|c|}
\hline 駕 & & & & & & & & \\
\hline 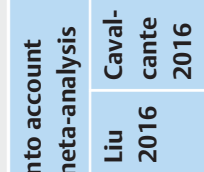 & $\times$ & $x$ & $\times$ & $\times$ & $\times$ & $x$ & $\times$ & $\times$ \\
\hline 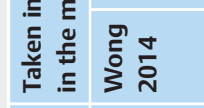 & & & & & & & & \\
\hline$=$ & & $\stackrel{\infty}{0}$ & 嘀 & $\frac{8}{0}$ & $\stackrel{\infty}{\circ}$ & $\stackrel{\circ}{=}$ & $\stackrel{\bar{t}}{0}$ & ĩ \\
\hline 三 & & 总高 & 离高 & 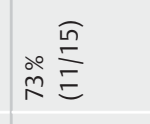 & 登舜 & 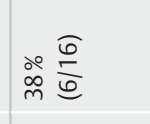 & 夷 & $\frac{x^{2}}{2}$ \\
\hline 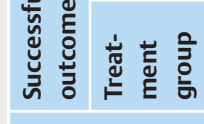 & & 范蓇 & 赵 & 品高 & 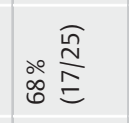 & 幽 & $\underset{\substack{\infty \\
0}}{\stackrel{\bar{N}}{E}}$ & 总高 \\
\hline 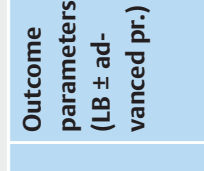 & & ì & $\frac{\dot{\phi}}{2}$ & $\frac{\dot{\phi}}{z}$ & $\frac{\dot{\phi}}{2}$ & $\frac{\dot{\bar{y}}}{2}$ & $\frac{\dot{i}}{2}$ & \\
\hline 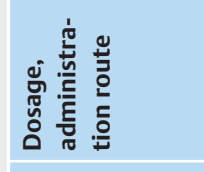 & & 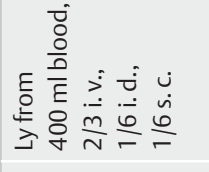 & 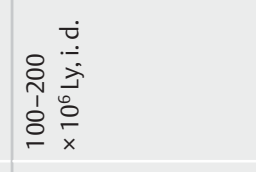 & 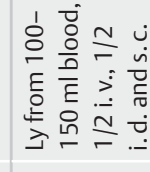 & 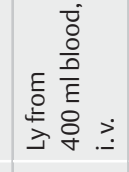 & 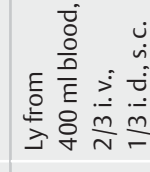 & 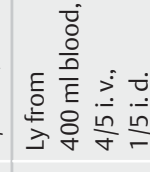 & 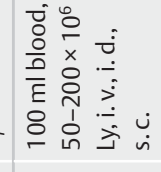 \\
\hline 总 & & ì & $\frac{\dot{\phi}}{2}$ & $\frac{\dot{\phi}}{2}$ & $\frac{\dot{\phi}}{2}$ & $\frac{\dot{\phi}}{2}$ & $\frac{\dot{\hat{\theta}}}{2}$ & \\
\hline 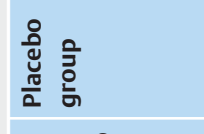 & & 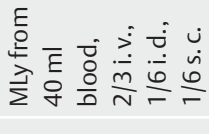 & 六 & $\frac{\bar{v}}{\underline{z}}$ & ते & हे & $\overrightarrow{\text { हे }}$ & 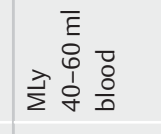 \\
\hline 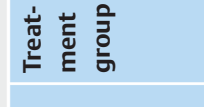 & & 를 & 㐔 & दे & 毬言 & दे & वे & \\
\hline 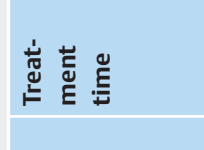 & & $\frac{\dot{\phi}}{2}$ & 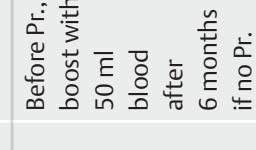 & 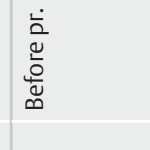 & 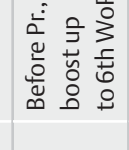 & 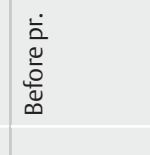 & 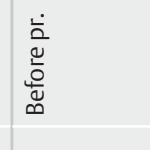 & 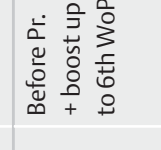 \\
\hline 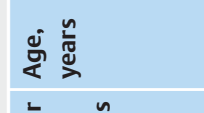 & & $\frac{\dot{i}}{2}$ & $\stackrel{\dot{m}}{2}$ & $\frac{\dot{\theta}}{2}$ & $\frac{\dot{\phi i n}}{2}$ & $\dot{\bar{\Delta}}$ & ì & $\frac{\dot{\theta}}{2}$ \\
\hline 离 & & m & in & $\bar{m}$ & g & $\stackrel{\sim}{\infty}$ & in & $\bar{m}$ \\
\hline 点 & & $\breve{\underline{\alpha}}$ & 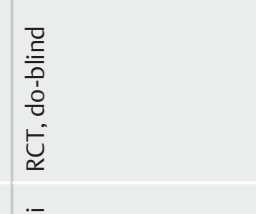 & $\stackrel{\breve{g}}{\underline{g}}$ & 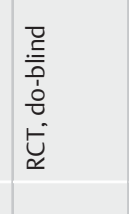 & $\begin{array}{l}\breve{z} \\
\bar{s}\end{array}$ & 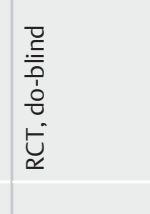 & 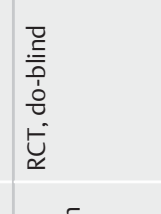 \\
\hline ขั๊ & 雨 & ᄒᄒ & 离 & 递 & 产 & 离 & $\frac{\frac{n}{\bar{D}}}{\frac{5}{2}}$ & 亮竘 \\
\hline 善 & 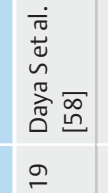 & & & & & & & \\
\hline
\end{tabular}




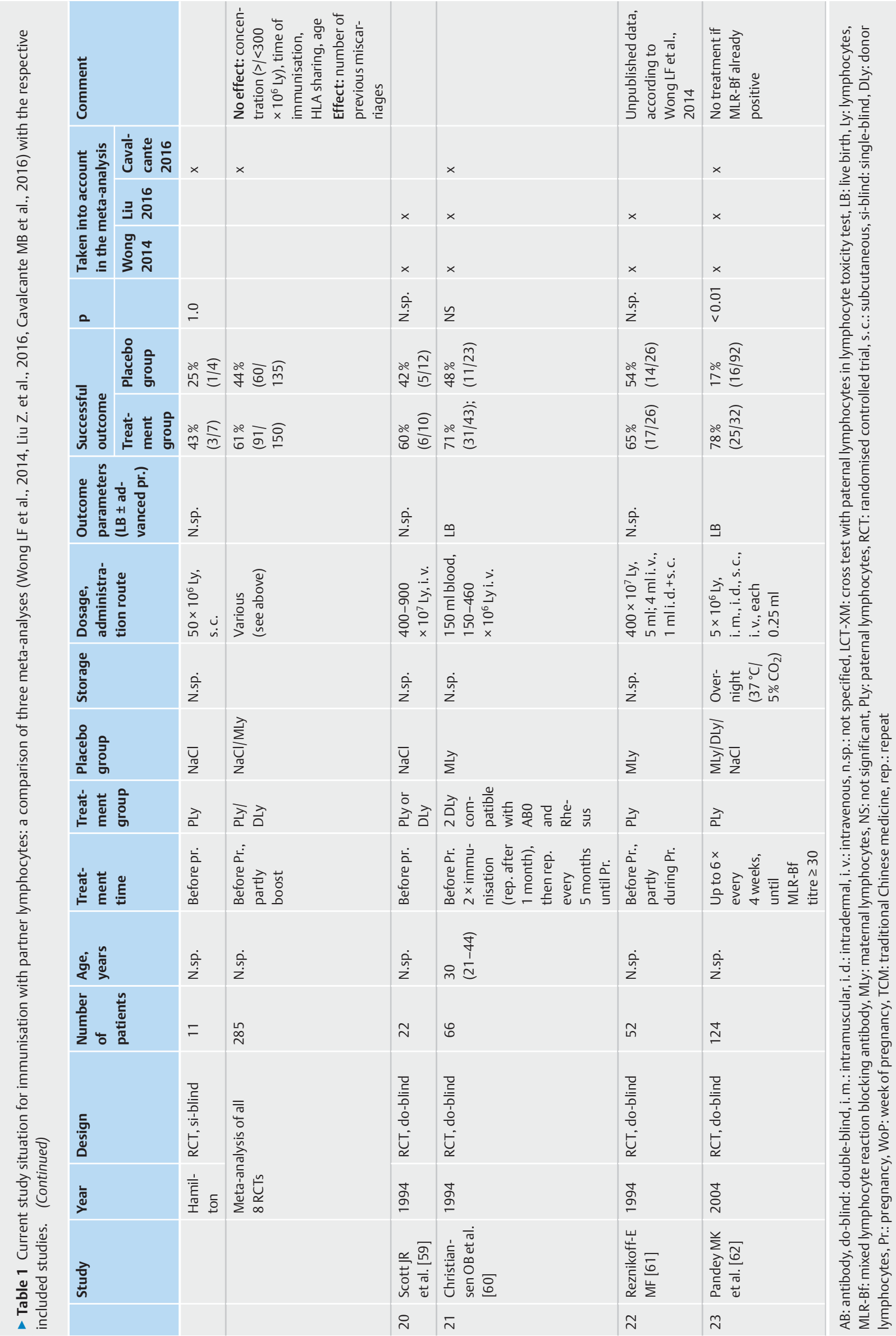


In 2001, the Cochrane Library published a meta-analysis of immunological treatment options for recurrent miscarriage, including lymphocyte immunisation. The last update of this meta-analysis in 2014 comprised 12 studies relating to immunotherapy with partner lymphocytes with a total of 641 patients, with 316 women in the case group and 325 women in the control/placebo group. No significant effect on the live birth rate following immunisation was demonstrated (OR 1.22, 95\% Cl 0.89-1.69) [28]. There was also no proof of an increased rate of live births for immunisation with donor lymphocytes (OR 1.39, 95\% Cl 0.68-2.82) [28].

The results of this Cochrane analysis are criticised by a range of scientists $[29,62,64]$. The main point of criticism was that the results of the study by Ober et al. [57] were included, which published the first and only data to date that showed a negative effect, i.e. even an increase in miscarriages, following immunotherapy.

Ober et al. stored the partner's blood, from which the lymphocytes were to be prepared, at a temperature of $1-6^{\circ} \mathrm{C}$ in order to be able to extend the period of time between the blood draw and immunisation. Clark et al. demonstrated that a sufficient number of CD200+ cells is required to achieve an immunomodulatory effect in immunotherapy with lymphocytes. CD200 is expressed on dendritic cells, among others, and can induce immunomodulation in the recipient within the context of immunisation. In this regard, the immunosuppressive component of the immune system is supported by the $T_{\text {reg }}$ cells with the help of the transforming growth factor beta (TGF- $\beta$ ) [65]. Storage at low temperatures reduces the CD200+ cell count [65]. Clark et al. argued that recurrent miscarriages following immunotherapy with lymphocytes must be attributed to genetic causes on the part of the embryo, an as yet undetected autoimmune disease in the patient or immunotherapy performed with an insufficient number of CD200+ cells [64].

Furthermore, Ober et al. included patients with autoimmune diseases (positive ANA titre) in the study, which has a negative effect on the results following immunotherapy with lymphocytes [57]. Further points of criticism were the lack of success monitoring (detection of antipaternal HLA antibodies) following immunisation, different methods of administration of the lymphocytes (intradermal, subcutaneous, intravenous) as well as different dosages and lymphocyte concentrations $[29,62,64]$.

A repeat analysis of the data from the Cochrane Library, excluding the results of Ober et al. [57], observed a significant increase in the rate of live births following immunisation with partner lymphocytes (OR 1.63, 95\% Cl 1.13-2.35; $p=0.009$ ) [28].

In 2014, Liu et al. published a new meta-analysis in the American Journal of Reproductive Immunology in order to correct the errors and/or weaknesses of the Cochrane analysis regarding this topic [38]. In this new meta-analysis, 18 randomised clinical studies from the period 1985-2013 were included; with a total of 1738 patients: 739 in the case group with immunisation with partner or donor lymphocytes and 999 patients in the control group. Liu et al. demonstrated a significant effect on the rate of live births following immunisation: $77.8 \%$ live births were recorded in the group following immunisation, compared with $46.1 \%$ in the control group (OR 4.02, 95\% Cl 3.23-5.00) [38]. A subgroup analysis regarding different immunisation protocols also revealed a significant increase in the rate of live births when the immunisation was performed before and during the pregnancy (OR 4.67, 95\% Cl 3.70-5.90 vs. OR 2.00, 95\% Cl 1.39-2.88) [38]. A further subgroup analysis indicated a better outcome when using no more than $100 \times 10^{6}$ lymphocytes per administration (OR 1.52, 95\% Cl 1.04-2.22) [38].

Yu et al. investigated the various methods of administration and demonstrated that the best results were achieved with intradermal immunisation [66].

In 2002, the US Food and Drug Administration (FDA) decided that active immunisation with partner lymphocytes would only be performed under study conditions. The reason for this was the aforementioned data of Ober et al. [57] from 1999. The current AWMF (Arbeitsgemeinschaft der Wissenschaftlichen Medizinischen Fachgesellschaften [German Association of the Scientific Medical Societies]) guideline $\mathbf{0 1 5 / 0 5 0}$ of 2013 is also circumspect with regard to this therapy. The reason for this is the lack of evidence of active partner immunisation for the treatment of recurrent spontaneous miscarriage. The only literature source indicated is a Cochrane analysis [67] from 2006, which also includes the work of Ober et al.

A recent review by Cavalcante et al. [39] from 2017 included 6 meta-analyses. Two of these - the above-mentioned works of Fraser et al. and Wong et al. - showed no increase in the rate of live births [28,63], while the other four demonstrated a significant effect with regard to the rate of live births following immunisation with partner lymphocytes [38, 39, 54, 56, 68].

\section{Conclusion}

Immunisation with partner lymphocytes is a treatment option for recurrent implantation failure or recurrent miscarriage if all other possible causes have been ruled out in advance. Due to the highly heterogeneous nature of the data, a significant benefit as a result of the immunisation cannot yet be clearly proven. However, there are signs that the therapy may be effective when using lymphocytes that have been extracted as short a time beforehand as possible. Overall, the treatment represents a safe, low-risk procedure. Following a detailed informative discussion with the couple regarding the chances of success and following a detailed review of the indication and contraindications, immunisation with partner lymphocytes can be discussed with the couple on a case-by-case basis, provided that all other possible causes of sterility have been ruled out in advance.

\section{Conflict of Interest}

The authors declare that they have no conflict of interest.

\section{References}

[1] Rai R, Regan L. Recurrent miscarriage. Lancet 2006; 368: 601-611

[2] Practice Committee of American Society for Reproductive Medicine. Definitions of infertility and recurrent pregnancy loss: a committee opinion. Fertil Steril 2013; 99: 63 
[3] Garrido-Gimenez C, Alijotas-Reig J. Recurrent miscarriage: causes, evaluation and management. Postgrad Med J 2015; 91: 151-162

[4] Steck T. Immuntherapie zur Abortprophylaxe und zur Verbesserung der Implantation bei der extrakorporalen Befruchtung. Zentralbl Gynäkol 2001; 123: 357-360

[5] Banchereau J, Briere F, Caux C et al. Immunobiology of dendritic cells. Annu Rev Immunol 2000; 18: 767-811

[6] Steinman RM, Hawiger D, Nussenzweig MC. Tolerogenic dendritic cells. Annu Rev Immunol 2003; 21: 685-711

[7] Hempstock J, Cindrova-Davies T, Jauniaux E et al. Endometrial glands as a source of nutrients, growth factors and cytokines during the first trimester of human pregnancy: a morphological and immunohistochemical study. Reprod Biol Endocrinol 2004; 2: 58

[8] Bischof P, Aplin JD, Bentin-Ley $U$ et al. Implantation of the human embryo: research lines and models. From the implantation research network 'Fruitful'. Gynecol Obstet Invest 2006; 62: 206-216

[9] Billington WD. The immunological problem of pregnancy: 50 years with the hope of progress. A tribute to Peter Medawar. J Reprod Immunol 2003; 60: 1-11

[10] Medawar P. Some immunological and endocrinological problems raised by the evolution of viviparity in vertebrates. Symposium of the Society for Experimental Biology 1953; 320

[11] Maejima M, Fujii T, Kozuma S et al. Presence of HLA-G-expressing cells modulates the ability of peripheral blood mononuclear cells to release cytokines. Am J Reprod Immunol 1997; 38: 79-82

[12] Krikun G, Lockwood C], Abrahams VM et al. Expression of Toll-like receptors in the human decidua. Histol Histopathol 2007; 22: 847-854

[13] Christiansen OB, Nielsen HS, Kolte AM. Future directions of failed implantation and recurrent miscarriage research. Reprod Biomed Online 2006; 13: 71-83

[14] Clark DA. Immunological factors in pregnancy wastage: fact or fiction. Am J Reprod Immunol 2008; 59: 277-300

[15] Li TC, Makris M, Tomsu M et al. Recurrent miscarriage: aetiology, management and prognosis. Hum Reprod Update 2002; 8: 463-481

[16] Santoni A, Carlino C, Gismondi A. Uterine NK cell development, migration and function. Reprod Biomed Online 2008; 16: 202-210

[17] Moffett A, Loke C. Immunology of placentation in eutherian mammals. Nat Rev Immunol 2006; 6: 584-594

[18] Pijnenborg R, Vercruysse L, Hanssens M. The uterine spiral arteries in human pregnancy: facts and controversies. Placenta 2006; 27: 939-958

[19] Bulmer JN, Lash GE. Human uterine natural killer cells: a reappraisal. Mol Immunol 2005; 42: 511-521

[20] Quenby S, Nik H, Innes B et al. Uterine natural killer cells and angiogenesis in recurrent reproductive failure. Hum Reprod 2009; 24: 45-54

[21] Wegmann TG, Lin H, Guilbert L et al. Bidirectional cytokine interactions in the maternal-fetal relationship: is successful pregnancy a TH2 phenomenon? Immunol Today 1993; 14: 353-356

[22] Raghupathy R, Makhseed M, Azizieh F et al. Cytokine production by maternal lymphocytes during normal human pregnancy and in unexplained recurrent spontaneous abortion. Hum Reprod 2000; 15: 713-718

[23] Lim KJ, Odukoya OA, Ajjan RA et al. The role of T-helper cytokines in human reproduction. Fertil Steril 2000; 73: 136-142

[24] Whitcomb BW, Schisterman EF, Klebanoff MA et al. Circulating levels of cytokines during pregnancy: thrombopoietin is elevated in miscarriage. Fertil Steril 2008; 89: 1795-1802

[25] Edmonds DK, Lindsay KS, Miller JF et al. Early embryonic mortality in women. Fertil Steril 1982; 38: 447-453

[26] Rogenhofer N, Mittenzwei S, Thaler C] et al. Stellenwert der aktiven Immuntherapie bei Kinderwunschpatientinnen. Gyn Endokrinologie 2011; 9: 215-218
[27] Kwak JY, Kwak FM, Gilman-Sachs A et al. Immunoglobulin G infusion treatment for women with recurrent spontaneous abortions and elevated CD56+ natural killer cells. Early Pregnancy 2000; 4: 154-164

[28] Wong LF, Porter TF, Scott JR. Immunotherapy for recurrent miscarriage. Cochrane Database Syst Rev 2014; (10): CD000112

[29] Takeshita T. Diagnosis and treatment of recurrent miscarriage associated with immunologic disorders: Is paternal lymphocyte immunization a relic of the past? J Nippon Med Sch 2004; 71: 308-313

[30] Wu L, Luo LH, Zhang YX et al. Alteration of Th17 and Treg cells in patients with unexplained recurrent spontaneous abortion before and after lymphocyte immunization therapy. Reprod Biol Endocrinol 2014; 12: 74

[31] Stray-Pedersen B, Stray-Pedersen S. Etiologic factors and subsequent reproductive performance in 195 couples with a prior history of habitual abortion. Am J Obstet Gynecol 1984; 148: 140-146

[32] Stray-Pedersen B, Stray-Pedersen S. Recurrent Abortion: the Role of Psychotherapy. In: Beard RW, Sharp F, eds. Early Pregnancy Loss, Mechanisms and Treatment. London, Berlin, Heidelberg: Springer; 1988: 433440

[33] Carp H], Toder V, Gazit E et al. Immunization by paternal leukocytes for prevention of primary habitual abortion: results of a matched controlled trial. Gynecol Obstet Invest 1990; 29: 16-21

[34] Mowbray JF. Autoantibodies, alloantibodies and reproductive success. Curr Opin Immunol 1989; 2: 761-764

[35] Beer AE. Pregnancy Outcome in Couples with recurrent Abortion following immunological Evaluation and Therapy. In: Beard RW, Sharp F, eds. Early Pregnancy Loss, Mechanisms and Treatment. Ashton-under-Lyne: Peacock Press; 1988: 337-349

[36] Kling C, Steinmann J, Westphal E et al. Adverse effects of intradermal allogeneic lymphocyte immunotherapy: acute reactions and role of autoimmunity. Hum Reprod 2006; 21: 429-435

[37] Kling C, Schmutzler A, Wilke G et al. Two-year outcome after recurrent implantation failure: prognostic factors and additional interventions. Arch Gynecol Obstet 2008; 278: 135-142

[38] Liu Z, Xu H, Kang X et al. Allogenic lymphocyte immunotherapy for unexplained recurrent spontaneous abortion: a meta-analysis. Am J Reprod Immunol 2016; 76: 443-453

[39] Cavalcante MB, Sarno M, Araujo Júnior E et al. Lymphocyte immunotherapy in the treatment of recurrent miscarriage: systematic review and meta-analysis. Arch Gynecol Obstet 2017; 295: 511-518

[40] Mowbray JF, Gibbings C, Liddell $\mathrm{H}$ et al. Controlled trial of treatment of recurrent spontaneous abortion by immunisation with paternal cells. Lancet 1985; 1: 941-943

[41] Cauchi MN, Lim D, Young DE et al. Treatment of recurrent aborters by immunization with paternal cells-controlled trial. Am J Reprod Immunol 1991; 25: 16-17

[42] Ho HN, Gill T] 3rd, Hsieh HJ et al. Immunotherapy for recurrent spontaneous abortions in a Chinese population. Am J Reprod Immunol 1991; 25: $10-15$

[43] Gatenby PA, Cameron K, Simes RJ et al. Treatment of recurrent spontaneous abortion by immunization with paternal lymphocytes: results of a controlled trial. Am J Reprod Immunol 1993; 29: 88-94

[44] Carp HJ, Toder V, Torchinsky A et al. Allogenic leukocyte immunization after five or more miscarriages. Recurrent Miscarriage Immunotherapy Trialists Group. Hum Reprod 1997; 12: 250-255

[45] Kilpatrick DCL, Liston W. Abstracts of contributors' individual data submitted to the worldwide prospective observation study on immunotherapy for treatment of recurrent spontaneous abortion. American Journal of Reproductive Immunology 1994; 32: 264

[46] Clark DA, Daya S. Trials and tribulation in the treatment of recurrent spontaneous abortion. Am J Reprod Immunol 1991; 25: 18-24 
[47] Pandey M, Halder A, Agarwal S. Immuno therapy in recurrent spontaneous abortion: randomized and non-randomized trials. Internet J Gynecol Obstet 2003; 2: 13

[48] Yanping C, Xiaoye Z, Qingmei B. Study of immunotherapy with lymphocytes in women with recurrent spontaneous abortion. Mod Prev Med 2011; 38: 1626-1627

[49] Lin S, Yan S, Shan E. Analysis the efficacy of immunotherapy with lymphocytes for recurrent spontaneous abortion. Jilin Med 2012; 33: 1822-1823

[50] Aiwu W, Mingzhu L, Runzhi W. Preventive treatment of unexplained recurrent spontaneous abortion and effect on pregnancy outcome by lymphocytes immunotherapy. China J Chin Med 2013; 28: 876-878

[51] Bin T, Kaishu H, Wenquan Z. Analysis of lymphocytes immunotherapy for recurrent spontaneous abortion. Chin Med Treat Works 2013; 21: 171172

[52] Hong L, Huaixiu W, Jing W. The lymphocyte injects and treats the habitual abortion that the immune factor causes. Med Mag Shanxi 2003; 32 : 308-309

[53] Stray-Pederson S. unpublished data, nach Wong LF et al. 2014. 1994

[54] [No authors listed]. Worldwide collaborative observational study and meta-analysis on allogenic leukocyte immunotherapy for recurrent spontaneous abortion. Recurrent Miscarriage Immunotherapy Trialists Group. Am J Reprod Immunol 1994; 32: 55-72

[55] Illeni MT, Marelli G, Parazzini F et al. Immunotherapy and recurrent abortion: a randomized clinical trial. Hum Reprod 1994; 9: 1247-1249

[56] Collins J, Roberts R. Immunotherapy for recurrent spontaneous abortion: analysis 1. Am J Reprod Immunol 1994; 32: 275-280

[57] Ober C, Karrison T, Odem RR et al. Mononuclear-cell immunisation in prevention of recurrent miscarriages: a randomised trial. Lancet 1999; 354: $365-369$

[58] Daya S, Gunby J. The effectiveness of allogeneic leukocyte immunization in unexplained primary recurrent spontaneous abortion. Recurrent Miscarriage Immunotherapy Trialists Group. Am J Reprod Immunol 1994; 32: 294-302
[59] Scott JR, Branch WD, Dudley DJ, Hatasaka HH. Immunotherapy for recurrent pregnancy loss: the University of Utah perspective. Reproductive Immunology. Serono Symposium Publications, Raven Press; 1997: 255257

[60] Christiansen OB, Mathiesen O, Husth M et al. Placebo-controlled trial of active immunization with third party leukocytes in recurrent miscarriage. Acta Obstet Gynecol Scand 1994; 73: 261-268

[61] Reznikoff-Etievant MF. Abstracts of contributors' individual data submitted to the worldwide prospective observation study on immunotherapy for treatment of recurrent spontaneous abortion. Am J Reprod Immunol 1994; unpublished data, nach Wong LF et al. 2014; 32: 266-267

[62] Pandey MK, Agrawal S. Induction of MLR-Bf and protection of fetal loss: a current double blind randomized trial of paternal lymphocyte immunization for women with recurrent spontaneous abortion. Int Immunopharmacol 2004; 4: 289-298

[63] Fraser EJ, Grimes DA, Schulz KF. Immunization as therapy for recurrent spontaneous abortion: a review and meta-analysis. Obstet Gynecol 1993; 82: 854-859

[64] Clark DA. The end of evidence-based medicine? Inflammopharmacology 2012; 20: 187-193

[65] Clark DA. Cell-surface CD200 may predict efficacy of paternal mononuclear leukocyte immunotherapy in treatment of human recurrent pregnancy loss. Am J Reprod Immunol 2009; 61: 75-84

[66] Yu HL, Deng XH, Chao L et al. [Study on positive rate of blocking antibody in women with recurrent spontaneous abortion administered by route and frequency of paternal lymphocyte immunotherapy]. Zhonghua Fu Chan Ke Za Zhi 2013; 48: 903-906

[67] Porter TF, LaCoursiere Y, Scott JR. Immunotherapy for recurrent miscarriage. Cochrane Database Syst Rev 2006; (2): CD000112

[68] Pandey MK, Thakur S, Agrawal S. Lymphocyte immunotherapy and its probable mechanism in the maintenance of pregnancy in women with recurrent spontaneous abortion. Arch Gynecol Obstet 2004; 269: 161172 